\title{
BMJ Open Device abandonment in deafblindness: a scoping review of the intersection of functionality and usability through the International Classification of Functioning, Disability and Health lens
}

\author{
Walter Wittich (D) , ${ }^{1,2}$ Sarah Granberg, ${ }^{3,4}$ Moa Wahlqvist (D) ,,5 \\ M. Kathleen Pichora-Fuller, ${ }^{6}$ Elina Mäki-Torkko ${ }^{4,5}$
}

To cite: Wittich W, Granberg S, Wahlqvist M, et al. Device abandonment in deafblindness: a scoping review of the intersection of functionality and usability through the International Classification of Functioning, Disability and Health lens. BMJ Open 2021;11:e044873. doi:10.1136/ bmjopen-2020-044873

- Prepublication history and additional materials for this paper is available online. To view these files, please visit the journal online (http://dx.doi org/10.1136/bmjopen-2020044873).

Received 17 September 2020 Revised 21 December 2020 Accepted 12 January 2021
Check for updates

(C) Author(s) (or their employer(s)) 2021. Re-use permitted under CC BY-NC. No commercial re-use. See rights and permissions. Published by BMJ.

For numbered affiliations see end of article.

Correspondence to

Dr Walter Wittich;

walter.wittich@umontreal.ca

\section{ABSTRACT}

Objectives Abandonment of vision, hearing or mobility aids suggests common barriers and facilitators to ongoing device use. However, the possible interactive effects of combined hearing and vision disabilities on device use by those living with deafblindness are unclear. Here we summarise existing knowledge on variables influencing assistive technology use from the perspective of persons living with deafblindness. We used the WHO's International Classification of Functioning, Disability and Health (ICF) framework to contextualise the findings, asking 'What is currently known about variables influencing the (non-) use of assistive devices recommended for persons with deafblindness?'

Design A scoping review followed the Preferred Reporting Items for Systematic Reviews and Meta-Analyses extension for Scoping Reviews Checklist.

Data sources PubMed; ProQuest: ERIC; ProQuest Dissertation; ProQuest: Sociological Thesaurus; Web of Science; Scientific Electronic Library Online; Bielefeld Academic Search Engine; Pascal \& Francis; APA PsycINF0 and Ebsco for CINAHL were searched through 9 November 2020.

Eligibility criteria We included peer-reviewed studies that reported on assistive technology, device abandonment/ utilisation and provided data from persons living with deafblindness.

Data extraction and synthesis Four team members independently scored 83 studies for eligibility.

Results Ten articles were chosen for data extraction. The emerging variables replicated established categories of barriers and facilitators: personal, device-related, environmental and intervention variables. The use of the ICF highlighted how an intermediate variable (eg, device acceptability) was necessary in order for a variable to become a barrier or a facilitator to device use.

Conclusions The variables influencing device use by persons with deafblindness followed the same categories described for single impairments. Usability was challenged in devices that rely on the 'other' sense. Haptic and tactile aids are rarely studied. The limited available information and the dire need for assistive technologies for people with deafblindness emphasises
Strengths and limitations of this study

- This scoping review pooled peer-reviewed resources across 10 online databases.

- Using the International Classification of Functioning, Disability and Health conceptual framework to contextualise device abandonment in deafblindness is an innovative approach to determining assistive technology intervention priorities.

- Generalisability of the findings is limited by the small sample sizes in the included studies.

- The variability and heterogeneity of persons living with deafblindness makes it difficult to capture a comprehensive picture of barriers and facilitators to assistive device use.

the urgency of research and technology development for this marginalised population.

The World Federation of the Deafblind ${ }^{1}$ estimated in 2018 that $0.2 \%-2 \%$ of the world's population were living with combined vision and hearing impairments. Individuals with hearing or vision impairment make up the second and third largest groups affected by an impairment globally, highlighting the level of burden caused by sensory loss. ${ }^{2}$ The population of persons living with combined vision and hearing impairment is heterogeneous because of differences in the order of, and age at, the onset of the impairments, as well as variability in impairment severity. ${ }^{3}$ This variability is paralleled in the terminology used to identify them; however, deafblindness is generally used as an umbrella term in the context of rehabilitation ${ }^{4}$ and throughout this manuscript. One commonality is that persons living with deafblindness heavily rely on, and benefit from, the use of assistive technologies. ${ }^{5} 6$ Traditionally, such devices are 
developed to overcome one specific impairment. In the presence of more than one impairment, however, unforeseen barriers can emerge that may hinder device users in successfully incorporating the devices into their lives. The present study aimed to explore what is currently known about the barriers to, and facilitators of, maintained use or abandonment of devices from the perspective of persons living with deafblindness. This knowledge is intended to guide the design of future devices and interventions to optimise device use in this population.

\section{BARRIERS AND FACILITATORS OF DEVICE USE OR ABANDONMENT IN SINGLE SENSORY IMPAIRMENT}

What is known about device use or abandonment in those with single vision impairment or hearing impairment has often been generalised to persons living with deafblindness. For assistive vision devices, barriers and facilitators have been grouped according to whether they are linked to the person, their environment, the device itself, or available interventions. ${ }^{7}$ For vision magnification devices, use is increased by higher self-confidence and motivation and perceived device benefit, while use is decreased by the associated stigma. ${ }^{8}$ For orientation and mobility, the stigma of using a white cane has received attention because it is the main identifier and symbol for blindness. ${ }^{9}{ }^{10}$ As for more contemporary technologies (eg, head-mounted displays), cybersickness and headaches influence device use. ${ }^{7}$ However, mainstream devices (eg, tactile tablets and smartphones) have been described as great equalisers and facilitators of device acceptance ${ }^{11}$; they are perceived as 'normal' when used in public, and are appreciated for their modern aesthetics. ${ }^{12}$

In hearing rehabilitation, device adoption is influenced by recognition of the need for the device, influence from family and friends or experience with other hearingassistive devices. ${ }^{13}$ The stigma associated with hearing aids has been studied extensively ${ }^{14-19}$ because, much like the white cane and blindness, this devices is the dominant symbol for hearing loss. The perception of hearing aids as a stigmatising symbol influences the choice to access and use assistive devices across age groups. ${ }^{20-23}$ One of the most in-depth analyses of variables related to hearing aid use and acceptance ${ }^{24}$ highlighted how dynamic this process can be, as the same variable may play different roles throughout the rehabilitative process. For example, motivation as influenced by other people plays an important positive role in early help seeking, while selfmotivation emerged as more important for later satisfaction with device use.

\section{BARRIERS AND FACILITATORS OF DEVICE USE OR ABANDONMENT IN DEAFBLINDNESS}

In the case of deafblindness, the same technologies that are available for single sensory impairments are commonly used. However, whether the barriers and facilitators that are experienced by persons with deafblindness are the same as those reported by single-impairment users is unclear. In addition, devices with a tactile or haptic interface (eg, braille displays or vibration notifications) take on additional importance, given that neither vision nor hearing may be sufficient to enable device use. What is also unknown is whether the use of multiple devices for several impairments can combine multiple experiences of stigma (also known as intersectional stigma ${ }^{25}$ ), and if one stigma may carry more weight than another. There are a few recognisable symbols that are associated specifically with deafblindness, such as the red-and-white striped cane, ${ }^{26}$ promoted by the World Federation of the Deafblind. ${ }^{27}$ It is unknown if the visibility of such devices has a similar stigmatising effect compared with the use of single sensory impairment technologies. Intersectional stigma has been studied in other fields, such as mental health, HIV/AIDS or motor impairments, ${ }^{25}$ but has so far not been explored in deafblindness.

\section{PARTICIPATORY ACTION APPROACH TO REMOVING BARRIERS}

Participatory action is an approach that empowers stakeholders to initiate action to address priority topics in healthcare. ${ }^{28}$ In the case of deafblindness, the lack of engagement of the community in participatory research reveals a systemic barrier. ${ }^{29}$ The development and implementation of innovative technology solutions has been identified as a priority in deafblindness by stakeholders ${ }^{5}$; however, its design frequently does not include device users, ${ }^{30} 31$ with few exceptions. ${ }^{32}{ }^{33}$ This is likely because research involving this population is possible but can be challenging. ${ }^{34} 35$ Individuals living with deafblindness have expressed multiple difficulties when it comes to the use, maintenance and usability of assistive devices and many have reported that simply knowing about the existence of possibly useful deceives can be a barrier, ${ }^{6}$ with lack of access to technology impeding independence and social participation. ${ }^{36-39}$ For the devices they do obtain, maintenance and care has not always been accomplished easily. ${ }^{6}$

\section{IDENTIFYING BARRIERS USING A CONCEPTUAL FRAMEWORK}

When focusing on functionality and usability issues for people living with deafblindness, a multifaceted approach might be necessary in order to understand the contributions of multiple relevant concepts. In rehabilitation disciplines, it is common to view functionality from a bio-psycho-social perspective, consistent with the perspective of the WHO's International Classification of Functioning, Disability and Health (ICF).$^{40}{ }^{41}$ One interpretation of how to understand functionality from this perspective is that a person should experience balance between the bodily (including the mind) aspects of a health condition, the performance of activities during participation in the everyday life and influential factors in the person's environment. The non-use of assistive devices could contribute to imbalance and might result 
in the experience of disability. Consequently, disability is always situational and highly determined by context. ${ }^{42}$ We used the ICF as a model for our research to explore the question: 'What is currently known about barriers and facilitators influencing the (non-) use of assistive devices recommended for persons with deafblindness?' Our goal was to provide stakeholders with an overview of the current state of knowledge on assistive device use and usability from the perspective of deafblind device users who had tried such technologies, and to present these findings within the conceptual framework of the ICF.

\section{METHODS}

Following the framework originally outlined by Arksey and O'Malley, ${ }^{43}$ the present scoping review followed their five stages: (1) identifying the research question, (2) identifying relevant studies, (3) selecting studies, (4) charting the data and (5) collating, summarising and reporting the results. The outcomes are presented following the Preferred Reporting Items for Systematic Reviews and Meta-Analyses extension for Scoping Reviews (PRISMA) Checklist, ${ }^{44}$ which is available in online supplemental appendix 1. The protocol was peer reviewed in the context of a grant funding proposal; however, it was neither registered nor published.

\section{Patient and public involvement statement}

This study did not directly involve patients or the public. The research question addressed in this study emerged through consultation with healthcare professionals who serve persons living with deafblindness ${ }^{5}$ and it aligns with the clinical experience of the authors. The sources in the articles included in this review were specifically chosen to be reports and data provided by persons living with deafblindness who use technologies. Dissemination to the public includes open-access online seminar presentations hosted by the Centre for Interdisciplinary Research in Rehabilitation (www.crir.ca).

\section{Identifying the research question}

This scoping review was guided by the question 'What is currently known about barriers and facilitators influencing the (non-) use of assistive devices recommended for persons with deafblindness?'. In order to facilitate the development of the search methodology and specific search terms, as well as to increase rigour in the search approach, ${ }^{45}$ the population and the relevant concepts and context of interest were defined in more detail. With regard to the population, the focus was on studies that answer the scoping question from the perspective of persons living with deafblindness who are users of assistive technology. Specifically, our focus was on use and/ or abandonment rather than on the initial uptake of technologies. Deafblindness was defined as broadly as possible, across all diagnoses and levels of severity, as well as the order and age of onset of the impairments. To implement this broad approach, the search included a variety of terminologies (eg, deafblindness, dual sensory impairment or low vision and hard of hearing), using both objective as well as subjective definitions. ${ }^{46-48}$ Barriers and facilitators were defined as variables that may help or hinder the use, maintenance, usability or abandonment of any assistive device or technology. We followed the WHO definition of assistive devices or technologies as 'those whose primary purpose is to maintain or improve an individual's functioning and independence to facilitate participation and to enhance overall well-being, ${ }^{49}$ All possible study contexts were included, whether educational, medical, technological, rehabilitative or otherwise. This approach allowed for the identification of barrier and facilitator variables informed by the lived experience of persons with deafblindness, making the results more easily generalisable.

\section{Identifying relevant studies}

In collaboration with a professional librarian, the following online databases were included in the search: PubMed; ProQuest: ERIC; ProQuest Dissertation; ProQuest: Sociological Thesaurus; Web of Science; SciELO (Scientific Electronic Library Online); BASE (Bielefeld Academic Search Engine); Pascal \& Francis; APA PsycINFO; and Ebsco for CINAHL. The search was conducted for papers published up to 9 November 2020, without limitations on languages or publication dates, using a combination of key words and medical subject headings (see online supplemental appendix 2). The search results were included in the data set if they fell in the overlap of the search criteria that defined the research question: (1) deafblindness; (2) assistive technology and (3) barriers/ facilitators. The three concepts were searched individually and were then combined using the AND operator of a Boolean search. In addition, a handsearch of the Journal of Deafblind Studies on Communication (https://jdbsc.rug. $\mathrm{nl} /$ ) was conducted because of this journal's relevance and the fact that it is not indexed in any searchable database except Google Scholar. No efforts were made to include grey literature. All identified study citations were downloaded into Endnote V.X9.2, where duplicates were identified and removed.

\section{Selecting studies: inclusion and exclusion criteria}

Four investigators (WW, SG, MW and EM-T) independently conducted a two-step screening process, first with titles and abstracts, and then with full-text articles, using the eligibility criteria (see table 1), with KP-F acting as the arbitrator for disagreements regarding inclusion/ exclusion decisions. Studies that reported group results for data from persons with deafblindness combined from persons with other disabilities were excluded if it was not possible to disentangle the data specific to persons with deafblindness. Theses and dissertations were excluded; however, the team tracked and included peer-reviewed articles based on these academic works. An overview of this process can be found in the PRISMA flow chart in figure 1. 
Table 1 Inclusion and exclusion criteria

\begin{tabular}{ll}
\hline Inclusion criteria & Exclusion criteria \\
\hline Article is peer reviewed. & $\begin{array}{l}\text { Dissertation, thesis or grey } \\
\text { literature. }\end{array}$
\end{tabular}

Article contains data from Article only contains data at least one person living provided by persons working with deafblindness with persons living with deafblindness (eg, educators, health professionals, administrators, family).
Article explores some type of assistive device or technology, as defined by WHO. ${ }^{49}$

\section{Article reports information} usability or abandonment technology designed for supporting vision or hearing function. on the use, maintenance, of any assistive device or

\section{Article reports data that are} combined across different disabilities, and sources of data from persons with persons living with deafblindness cannot be clearly identified.

Article reports only on assistive devices that are not directly related to vision or hearing (eg, wheel chair).

\section{Charting the data}

Through consultation among the authors and in line with previous scoping reviews conducted by members of our team, ${ }^{80-52}$ it was decided to extract the following variables and to chart them in the form of an Excel spread sheet: article title, name of authors, year of publication, journal citation details, location/country of study, study design, methodology, participant description, number of participants, terminology used for deafblindness, assistive

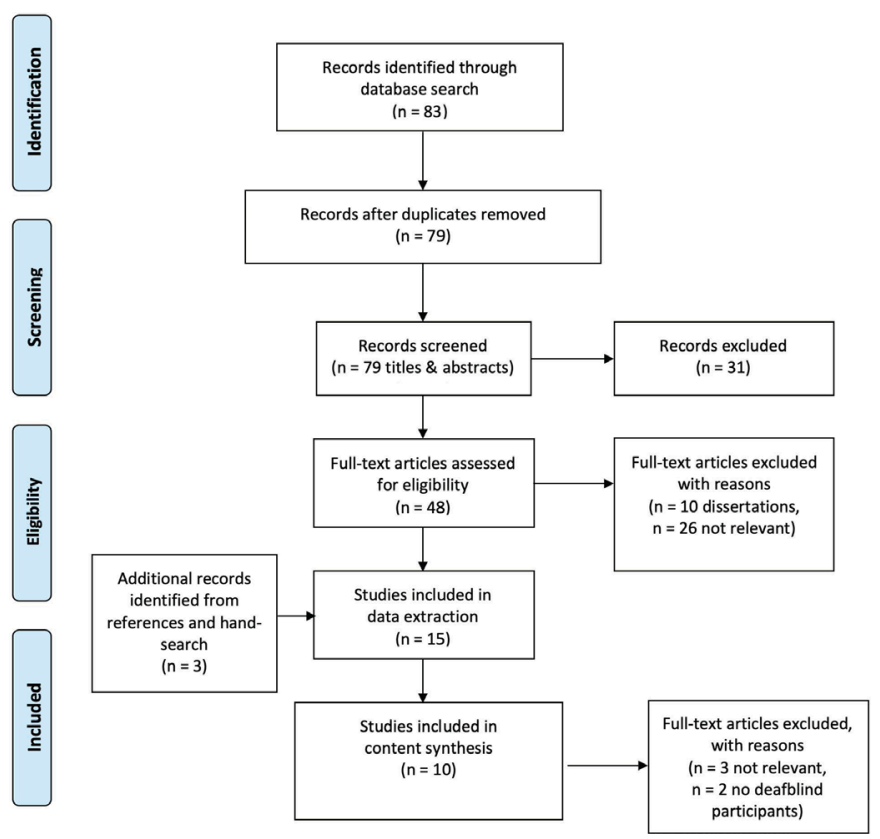

Figure 1 Preferred Reporting Items for Systematic Reviews and Meta-Analyses flow chart, demonstrating the study selection process. technologies investigated, facilitators and barriers to device use, main focus of the article, and comments on any other information significant to the scoping review question. The findings from the included papers concerning facilitators and barriers to device (non-) use were linked to the component level of the ICF. The ICF is a well-recognised conceptual framework for functioning, disability and health that serves the goal of providing a scientific base for understanding functioning and health. ${ }^{41}$ Since its adoption in 2001, the ICF has entered clinical and scientific arenas and it is commonly used in developing health policies and guidelines worldwide. The model is a useful tool when interpreting scientific data from a functional perspective. Merging, or linking, components of the ICF pertaining to study objectives or data is performed by guidelines called 'linking rules'. ${ }^{53-55}$ When linking to the ICF model, the data can, for example, be organised into the different ICF components denoted as body functions or structures (physiological or psychological functions of body systems and anatomical parts of the body), activities and participation (the execution of task or actions by an individual and involvement in a life situation), environmental factors (physical, social and attitudinal environment of individuals) and personal factors (background of an individual's life and living, not part of a health condition) ${ }^{41}$

\section{RESULTS}

\section{Collating, Summarising and reporting the results}

Following the guidelines of Arksey and O'Malley, ${ }^{43}$ as well as those of Levac and colleagues,${ }^{56}$ we used summary quantitative techniques as well as qualitative description for reporting the results. ${ }^{57}$ The summary of descriptive information about the included studies is provided in table 2, with papers sorted chronologically by publication date. The synthesis of the qualitative information on barriers and facilitators was conducted in collaboration with all team members and is presented in figure 2 . This figure was inspired by a report presented by Knudsen $e t$ $a l^{44}$ regarding hearing device use, and follows a layout presented by Lorenzini and Wittich ${ }^{8}$ in a study exploring variables related to magnification device use. Figure 2 shows four categories of variables identified as barriers to or facilitators of the use of assistive technologies and their overlap: personal, environmental, device-related or intervention-based variables.

\section{Study characteristics}

The PRISMA flow chart in figure 1 summarises the details of the study identification and screening process. Three studies were added to the 83 identified studies using the search strategy, based on the results of the hand-search of the Journal of Deafblind Studies on Communication and a search of items that emerged from reference lists during the full-article review. Only 10 studies ${ }^{173758-65}$ were eligible to be included in the data extraction process. They were all published in or after 2012, with research teams and 
Table 2 Included studies

\begin{tabular}{|c|c|c|c|c|}
\hline Authors and citation & Year & Journal title & Study country & Study design \\
\hline Emerson and Bishop ${ }^{58}$ & 2012 & $\begin{array}{l}\text { Journal of Visual } \\
\text { Impairment \& Blindness }\end{array}$ & USA & Mixed methods \\
\hline Meyer et $\left.a\right|^{59}$ & 2014 & $\begin{array}{l}\text { International Journal of } \\
\text { Audiology }\end{array}$ & Australia & Quantitative survey \\
\hline Cantin et $a l^{61}$ & 2019 & $\begin{array}{l}\text { Journal of Deafblindness } \\
\text { Studies on } \\
\text { Communication }\end{array}$ & Canada & Case Study, mixed methods \\
\hline St-Amour et al ${ }^{62}$ & 2019 & $\begin{array}{l}\text { Optometry \& Vision } \\
\text { Science }\end{array}$ & Canada & $\begin{array}{l}\text { Quantitative within-between } \\
\text { experimental study }\end{array}$ \\
\hline Jaiswal et al ${ }^{64}$ & 2020 & Frontiers in Education & Canada & $\begin{array}{l}\text { Qualitative semistructured } \\
\text { interviews }\end{array}$ \\
\hline Parker et a/ ${ }^{65}$ & 2020 & Frontiers in Education & USA & Focus Groups \\
\hline
\end{tabular}

participants located primarily in high-income countries (USA, Czech Republic, England, Italy, Spain, Poland, France, Australia, Canada) and with one study in India. Sample sizes of recruited persons with deafblindness

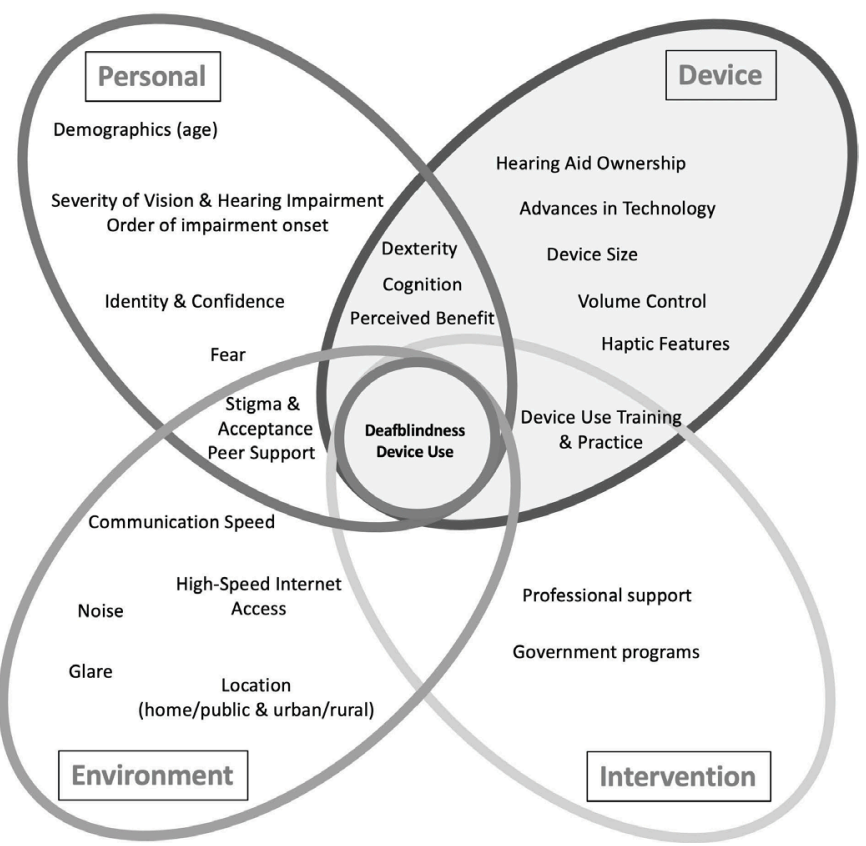

Figure 2 Variables influencing assistive device use, adoption, uptake, maintenance, usability or abandonment, from the perspective of persons living with deafblindness. The variables that emerged during the scoping review were suitable to fit previously identified categories from studies on single impairments. ranged from 1 to 86 ( mean=23.7, $\mathrm{SD}=24.8$, median=16), including two case studies focused on the same participant. ${ }^{6163}$ Severity of the communication challenges varied from individuals with more severe levels of deafblindness who relied on tactile communication ${ }^{1737616365}$ to persons with partial acquired deafblindness who communicated verbally using spoken language. ${ }^{59} 606264$ The studies included students, ${ }^{3758}$ working age adults ${ }^{17376163}$ and older adults. ${ }^{59606264}$ Research methodologies included qualitative, $^{17} 3758 \quad 63-65$ quantitative ${ }^{59} \quad 60 \quad 62$ and mixedmethods approaches. ${ }^{61}$ Deafblindness was defined using medical model quantitative thresholds based on visual acuity and pure-tone audiogram measurements, ${ }^{60-64}$ self-institutional identifiers ${ }^{17} 375865$ or questionnaire responses. ${ }^{59}$ Two studies ${ }^{6163}$ made reference to the Nordic Definition of Deafblindness, ${ }^{66}$ while one study ${ }^{17}$ referred to the European Parliament' Written declaration on the rights of deafblind people, describing deafblindness as a unique disability. ${ }^{67}$

The technologies and assistive devices studied in the research projects included aids designed to overcome limitations caused by single or dual impairments. Technologies for hearing impairment were the following: personal amplification system, ${ }^{60}$ telephone amplifier, ${ }^{60}$ hearing aids. ${ }^{17375964}$ Technologies for vision impairment were the following: talking clock or watch, ${ }^{60}{ }^{62}$ talking calculator, ${ }^{62}$ talking scanner, ${ }^{62}$ white cane, ${ }^{17} 64$ braille technology ${ }^{37} 64$ and different types of magnification devices. ${ }^{64}$ In addition, mainstream technologies that could be connected or incorporated to overcome barriers unique to combined vision and hearing impairment were 
explored: tablet computers, ${ }^{64}$ videophone technology together with 22 -inch television monitor, ${ }^{58}$ braille display notetaker connected via Bluetooth to an iPhone, ${ }^{61} 63$ and global positioning technology linked to a smartphone and apps. ${ }^{65}$ Aside from the use of braille, only one study made references to a haptic feature of a device, mentioning the vibrating functions available with certain smartphones. ${ }^{65}$

\section{Barriers and facilitators}

Figure 2 presents an overview of the variables influencing the use, usability, maintenance or abandonment of assistive technologies based on data provided by persons living with deafblindness who use assistive devices. These variables are organised into four categories: personal, environmental, device related or intervention related.

\section{Personal category}

Among the variables influencing device use that are mainly intrinsic to the person, older age was associated with more difficulties using devices. ${ }^{60}$ Physically, this effect was related to declines in dexterity, as well as with more severe levels of vison and hearing impairment. The degree of hearing loss as well as the severity of vision loss also influenced participants' confidence in their ability to manage devices such as hearing aids. ${ }^{59}$ Interestingly, one study ${ }^{17}$ reported that participants expressed the opinion that the order of onset of their sensory impairments played a role in their willingness or ability to accept a device. In cases where one impairment developed after the other, devices associated with the second impairment became more difficult to accept or integrate into their lives. This difficulty was attributed to the associated need to change their disability identity, moving towards deafblindness as opposed to a single impairment identity.

In the context of personal variables that are linked to the environment and the people therein, there was a strong influence of psychosocial variables on device use. A sense of identity as a deafblind person emerged as important, with individuals who had succeeded at accepting their situation being more successful in incorporating technology into their lives and having more competence and confidence in their ability to use technology. ${ }^{17} 6163$ Barriers were often experienced when participants were dealing with fear while using devices, specifically around others and when outdoors or in public, with these fears being related to a general experience of stigmatisation by others and self-stigma. ${ }^{17} 61$ Peer and family support appeared to alleviate some of these difficulties by helping individuals living with deafblindness to reject stigmatising stereotypes. ${ }^{176364}$ However, the opposite was also reported insofar as preconceived ideas by others about the abilities of a deafblind person could result in negative behaviours or discouraging attempts to try a potentially useful device. ${ }^{58}$ One case study ${ }^{61}$ specifically mentioned that the speed, richness and fluidity of interacting with a communication partner in a public setting strongly influenced the decision about whether or not to use a communication device as compared with using alternative traditional techniques (eg, tactile interpretation) that were generally faster, even though dependent on the presence of an interpreter.

\section{Environmental category}

Successful device use depended on environmental variables that are often outside the device-user's control, including the presence of noise, availability of access to high-speed internet ${ }^{58}$ or other conditions at specific locations (at home vs in public) of the device user. ${ }^{17}$ For example, there could be differences between using assistive devices in public versus at home both in terms of familiarity with the environment, but also in terms of the context of using the device alone versus in front of others, with risk of stigma being higher in interactions with others, especially in public situations. One study specifically commented on how experiences of using assistive devices differed between rural vs urban environments. ${ }^{17}$ The study conducted with participants in India highlights the effect of the absence of resources; for example, the acquisition of devices is not possible when they are either not available to or unobtainable by persons with deafblindness. $^{37}$

\section{Device-related category}

Variables that are intrinsic to specific technologies and that can influence device use included device size, ${ }^{1761}$ the ability to control the volume, ${ }^{62}$ or overall device sound quality, device malfunctions and device cost. $^{37}$ For example, participants commented that smaller devices facilitated travel and use, while the possibility to use a volume control was reported as a potential advantage for improving speech understanding when using a hearing aid. Beyond device characteristics, advances in technology development that improve its capacity were praised. ${ }^{17}$ Participants across different studies indicated that the efficiency and effectiveness of a device in accomplishing what it is designed to do (eg, communicate with someone at reasonable speed) were important to users. ${ }^{61}$ Not surprisingly, simply having access to ${ }^{37}$ or owning the necessary device itself (eg, having access to a hearing aid) emerged as a contributor to improved ability. ${ }^{59}$

\section{Intervention-related category}

Very few aspects of device provision or the amount or type of rehabilitative intervention were investigated. One study explored the benefit of instructions on strategies for using devices (training) versus the effect of simply practising device use (repetition), indicating that both variables had beneficial and apparently independent and additive effects. ${ }^{60}$ In addition, the option of repeating recorded information through a device was reported to be beneficial for hearing. ${ }^{62}$ Furthermore, access to and availability of technical support emerged as a variable that became relevant when problems arose with device use in the field, ${ }^{6163}$ with the need for support in these situations often being fulfilled by friends or family ${ }^{17}$ as well as by the availability of support through government services. ${ }^{64}$ 


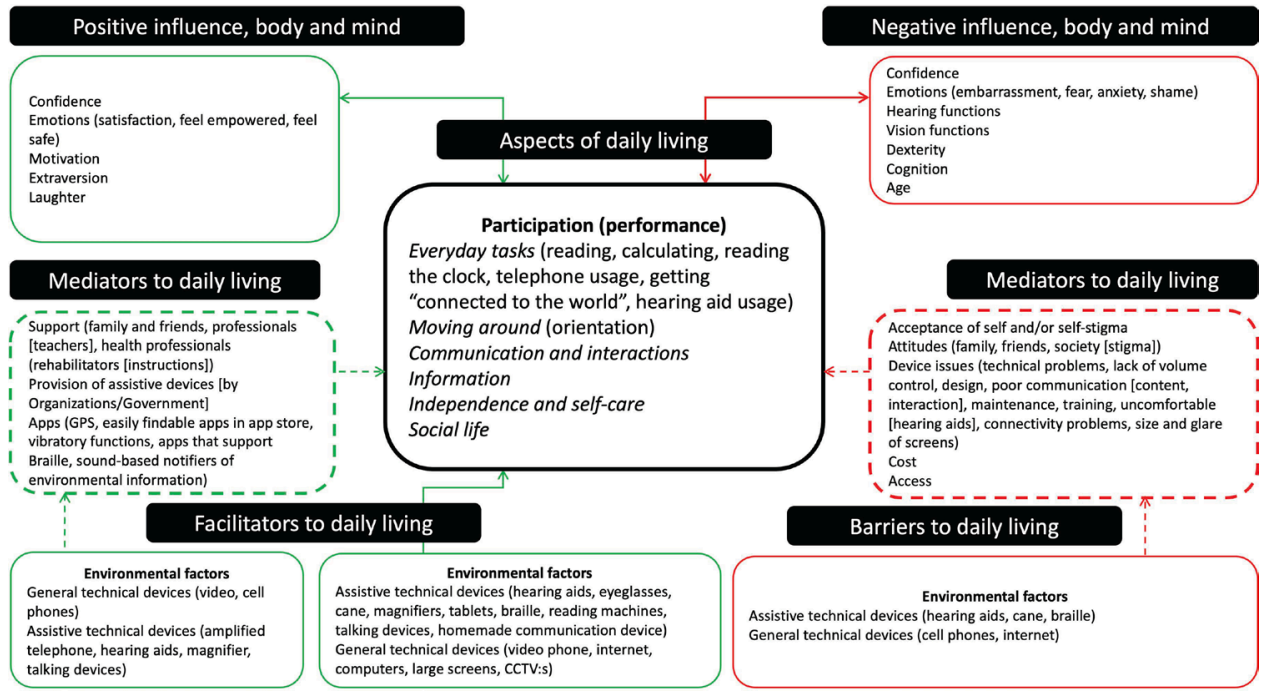

Figure 3 Schematic overview of how environmental variables can act as facilitators or barriers on aspects of daily living, either directly or as mediators, affecting body and mind. The model uses linking rules from the International Classification of Functioning. CCTV = closed-circuit television; GPS = global positioning system

\section{Variables in overlapping categories}

The purpose of figure 2 is to demonstrate that the division of variables into these four categories is not as clean-cut as parts of the description here might suggest at first glance. Several of these variables depend on an intricate interplay between at least two categories. For example, considering stigma and stereotyping, it rapidly becomes clear that the perceptions by the individual using the device are influenced by the device itself and the context of it being used such as in an environment that involves other people, especially in public settings. This multifactorial interaction has been explored and described in single-sensory

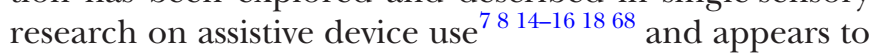
be similarly complex in deafblindness.

\section{An ICF perspective on facilitators and barriers to technology use}

The included papers investigated several aspects of everyday life that were implicated in the use of the different technologies (see figure 3). These aspects concerned everyday tasks (eg, reading or telephone usage), orientation and mobility (eg, independent travel), communication, social interactions and information exchange (eg, telephone usage), independence and self-care (eg, accessing and paying bills, going to school) and participation in social activities (eg, accessing entertainment and online events). The different technologies that were studied related to hearing (eg, hearing aids), vision (eg, cane or magnifier) or more general technologies (eg, the internet). The properties and characteristics of assistive devices themselves could be both facilitators of and barriers to their use, but sometimes a mediator was necessary in order for the technology to become a barrier to or a facilitator of its use. Mediators related to barriers to technology use could be human-related (non-acceptance by the individual of his/her own situation, attitudes of others, stigma by others in society or self-stigmatisation), technology-related factors (eg, cost or design) or factors related to societal aspects (eg, accessibility legislation). Some aspects specifically related to the technology that hindered its use, including design issues such as the lack of proper volume control, challenges managing maintenance (eg, changing batteries) and trouble-shooting and solving technical problems (eg, malfunctions).

The device-related variables that were considered facilitators pertained to both assistive devices and, what ICF refers to as, general devices (eg, video phones or the internet). Here, the facilitators had a direct link to aspects of everyday living, but sometimes a mediator was required in order for the device to be a facilitator. The mediators could be human-related (eg, support from professionals and family) or device-related (eg, volume control, vibrating feature). Bodily (and mind) aspects of disability could be positively affected by variables such as increased confidence, positive emotions and motivation; however, they could also be negatively affected when the devices were barriers (eg, when they decreased confidence and increased negative emotions).

\section{DISCUSSION}

The purpose of the present study was to summarise what is known about facilitators and barriers to the use of assistive devices from the perspective of persons living with deafblindness. The findings were interpreted within the conceptual framework of the ICF. The evidence that emerged from the reviewed studies indicates that previously presented groupings of relevant variables can also be applied to the perceptions of persons living with deafblindness. These personal, device-related, environmental and intervention barriers and facilitators have been described in studies of device use by people with vision impairment $^{7869}$ or hearing impairment ${ }^{24}$ alone. However, this general pattern of findings must be interpreted cautiously because almost all devices in the included 
studies were designed for single sensory impairment (eg, hearing aids, braille display) but used by persons with deafblindness. Therefore, this agreement in findings for those with single and dual sensory impairments is not entirely surprising. The present study of those with deafblindness could be considered as a replication of previous studies conducted in target groups with single sensory impairments.

One of the most intriguing findings, however, was the dearth of research on assistive technologies that used the sense of touch to meet the needs of persons living with deafblindness (aside from braille as access to print). Only one study mentioned the vibration features of smartphones as a useful notification feature ${ }^{65}$ insofar as participants expressed their desire to include haptic options to supplement the existing accessibility options of mainstream devices. The lack of research papers investigating the use of haptic/tactile assistive technology may reflect the state of technology development and its current implementation for device users who are deafblind. ${ }^{5}$ There are likely several reasons for this scarcity of applied haptic/ tactile assistive technology research, including the difficulties in recruiting participants from such a small and marginalised population, the challenges of conducting research when communication with participants requires extensive accessibility adaptations, ${ }^{35}$ and the financial feasibility of technology development for the special needs of such a small user group. Nevertheless, current trends in the disability profile of users of assistive devices indicate that it is becoming more common for people to have multiple impairments. ${ }^{70}$ It is likely that this trend will promote increasing awareness of a growing need for assistive technology based on universal design ${ }^{71}$ that remains usable even in the presence of multiple impairments (including sensory impairments). Therefore, assistive devices that use haptics would not only make these technologies more accessible for persons with deafblindness, but would likely also increase usability for persons of all ages who have other disabilities for which the use of haptics could enable access to and use of devices to support improved functioning.

When viewing the study components through the lens of the ICF, several interesting patterns emerged that provide insights into how assistive technology can tip the scale to achieve the person/environment balance for persons living with deafblindness. Environmental variables can potentially act as barriers (eg, the presence of noise) or facilitators (eg, free access to high-speed internet), depending on how they affect activities of daily living directly, or they may contribute indirectly as mediators. Similarly, body and mind variables have the same potential to work for or against the individual's ability to complete activities independently with the use of technology. When task performance was improved (when the device-related factors successfully acted as facilitators to use), then the resulting positive effects could also affect the body and mind; in contrast, when performance was not supported by device use because of device-related factors, the resulting effects on body and mind could be negative. Therefore, in order to optimally support the balance between the abilities of a person with deafblindness and the demands imposed in their environments, device-related factors must successfully act as facilitators of device use. Otherwise, a poorly designed or inaccessible device can be deleterious, potentially causing frustration, unnecessary dependence and ultimately device abandonment, even if the individual makes an initial attempt to use it.

In order to optimise assistive technology outcomes, rehabilitation interventions using the appropriate assistive technologies can strengthen the individual psychologically, increasing self-efficacy and reducing stigma or self-stigma. A positive feedback loop could be fostered by systematically demonstrating the positive effects of device use first in relative favourable environments and gradually increasing technology usage in more challenging environments as needed in a broader range of activities of daily living. Also, by carefully selecting devices that actually target both hearing and vision simultaneously (eg, volume controls with large buttons), rehabilitation professionals could focus on their clients' goals while considering both senses rather than only one sense at a time. Even though the included papers only considered assistive devices for vision or hearing impairment alone rather than devices that were specifically designed for our deafblind target group, a joint focus on both sensory impairments could result in interventions that are more successful in achieving the rehabilitative goals of people living with deafblindness.

\section{Limitations and future directions}

As a general limitation in the field of deafblindness, our synthesis is limited by the small sample sizes of participants in the included studies; however, the samples do provide coverage of a large age range and people living in a number of different countries. Interestingly, many of the facilitators and barriers were reported across age groups (younger, working-age and older adults), but it is still difficult to generalise the findings. A second limitation that is inherent to working with this population is the individuality and variability in their many defining characteristics. The included studies report on persons with partial as well as complete sensory losses, early or late onset, multiple communication modalities and various levels of dependency on tactile interfaces. This variability, in part, explains the type and range of devices that were investigated. In addition, the total number of studies that were included in the review was small, with only one from a low-income or middle-income country and none from Africa. This paucity of studies is consistent with the early stage of development and sophistication that assistive device usability research in deafblindness has reached. Over the coming decade, the increased prevalence of deafblindness in older adults, coupled with the rapid evolution of technological possibilities, will likely foster much growth in research on the design and the use of 
traditional as well as mainstream assistive technology for persons with deafblindness. Ideally, the relevance of this research will be guided by an integrated knowledge translation approach, ${ }^{72}$ such that persons living with deafblindness will be part of this evolution and will be included along the entire spectrum of the research process as partners in the codesign and evaluation of new assistive technologies. ${ }^{73}$

\section{CONCLUSION}

Assistive technology is intended to improve quality of life, participation and independence for persons with disabilities by enhancing the individual's abilities and minimising environmental barriers. For persons living with deafblindness, the interactive effects of combined vision and hearing impairment often impede the usability of assistive devices. Our synthesis of the existing peer-reviewed literature indicates that device use, maintenance, usability or abandonment by persons with deafblindness have almost exclusively been studied for devices that are designed for unisensory hearing or vision impairment, but not for dual sensory impairments. The minimal attention on research with haptic technologies, specifically those designed for communication, reveals an important gap. This gap may be resolved by using a multidisciplinary and integrated knowledge translation approach that increases efforts to develop and evaluate such devices in partnership with device users.

\section{Author affiliations}

${ }^{1}$ School of Optometry, Université de Montréal, Montréal, Québec, Canada

${ }^{2}$ Institut Nazareth et Louis-Braille du Centre Intégré de Santé et de Services Sociaux de la Montérégie-Centre, Longueuil, Québec, Canada

${ }^{3}$ School of Health Sciences, Faculty of Medicine and Health, Örebro University,

Örebro, Sweden

${ }^{4}$ Audiological Research Centre, Faculty of Medicine and Health, Örebro Universitet, Örebro, Sweden

${ }^{5}$ Swedish Institute for Disability Research, Örebro, Sweden

${ }^{6}$ Department of Psychology, University of Toronto - Mississauga, Mississauga, Ontario, Canada

\section{Twitter Walter Wittich @WalterWittich}

Acknowledgements We would like to express our thanks to Francine Baril for developing the search terms and conducting the article search. A special thank you goes to Professor Claes Möller for initiating this collaborative team.

Contributors WW, KP-F and EM-T planned the study and obtained grant funding. WW, SG, MW, KP-F and EM-T conducted the review, completed the analyses and cowrote the manuscript.

Funding This work was supported by the Centre for Interdisciplinary Research in Rehabilitation of Greater Montreal, the University Hospital Örebro, and the Fonds de Recherche du Québec-Santé grant number 281451.

Competing interests None declared.

Patient consent for publication Not required.

Provenance and peer review Not commissioned; externally peer reviewed.

Data availability statement Data sharing not applicable as no datasets generated and/or analysed for this study. No data are available. All data are available in the public domain.

Supplemental material This content has been supplied by the author(s). It has not been vetted by BMJ Publishing Group Limited (BMJ) and may not have been peer-reviewed. Any opinions or recommendations discussed are solely those of the author(s) and are not endorsed by BMJ. BMJ disclaims all liability and responsibility arising from any reliance placed on the content. Where the content includes any translated material, BMJ does not warrant the accuracy and reliability of the translations (including but not limited to local regulations, clinical guidelines, terminology, drug names and drug dosages), and is not responsible for any error and/or omissions arising from translation and adaptation or otherwise.

Open access This is an open access article distributed in accordance with the Creative Commons Attribution Non Commercial (CC BY-NC 4.0) license, which permits others to distribute, remix, adapt, build upon this work non-commercially, and license their derivative works on different terms, provided the original work is properly cited, appropriate credit is given, any changes made indicated, and the use is non-commercial. See: http://creativecommons.org/licenses/by-nc/4.0/.

\section{ORCID iDs}

Walter Wittich http://orcid.org/0000-0003-2184-6139

Moa Wahlqvist http://orcid.org/0000-0002-6965-6820

\section{REFERENCES}

1 World Federation of the Deafblind. At risk of exclusion from CRPD and SDGs implementation: inequality and persons with deafblindness. Oslo, Norway: World Federation of the Deafblind, 2018.

2 Vos T, Allen C, Arora M, et al. Global, regional, and national incidence, prevalence, and years lived with disability for 310 diseases and injuries, 1990-2015: a systematic analysis for the global burden of disease study 2015. Lancet 2016;388:1545-602.

3 Dammeyer J. Deafblindness: a review of the literature. Scand J Public Health 2014;42:554-62.

4 Lagati S. 'Deaf-blind' or 'Deafblind'? International perspectives on terminology. J Vis Impair Blind 1995;89:306.

5 Wittich W, Jarry J, Groulx G, et al. Rehabilitation and research priorities in Deafblindness for the next decade. J Vis Impair Blind 2016;110:219-31.

6 LeJeune BJ. Aging with dual sensory loss: thoughts from consumer focus groups. AER J Res Pract Vis Impair Blind 2010;3:146-52.

7 Lorenzini M-C, Hämäläinen AM, Wittich W. Factors related to the use of a head-mounted display for individuals with low vision. Disabil Rehabil 2019:1-15.

8 Lorenzini M-C, Wittich W. Factors related to the use of magnifying low vision AIDS: a scoping review. Disabil Rehabil 2020:42:3525-37.

9 Hersh M. Cane use and late onset visual impairment. Technol Disabil 2015;27:103-16.

10 Wainapel SF. Attitudes of visually impaired persons toward cane use. $J$ Vis Impair Blind 1989;83:446-8.

11 Martiniello N, Eisenbarth W, Lehane C, et al. Exploring the use of smartphones and tablets among people with visual impairments: are mainstream devices replacing the use of traditional visual AIDS? Assist Technol 2019:1-12.

12 Dos Santos ADP, Ferrari ALM, Medola FO, et al. Aesthetics and the perceived stigma of assistive technology for visual impairment. Disabil Rehabil Assist Technol 2020;0:1-7.

13 Jorgensen L, Novak M. Factors influencing hearing aid adoption. Semin Hear 2020;41:6-20.

14 McKee MM, Choi H, Wilson S. Determinants of hearing aid use among older Americans with hearing loss. Gerontologist2018:gny051.

15 Erler SF, Garstecki DC. Hearing loss- and hearing aid-related stigma: perceptions of women with age-normal hearing. Am J Audiol 2002;11:83-91.

16 Johnson CE, Danhauer JL, Gavin RB, et al. The 'hearing aid effect' 2005: a rigorous test of the visibility of new hearing aid styles. Am J Audiol 2005;14:169-75.

17 Hersh MA. Deafblind people, stigma and the use of communication and mobility assistive devices. Technol Disabil 2013;25:245-61.

18 Wallhagen MI. The stigma of hearing loss. Gerontologist 2010;50:66-75

19 David D, Werner P. Stigma regarding hearing loss and hearing AIDS: a scoping review. Stigma and Health 2016;1:59-71.

20 Southall K, Gagné J-P, Jennings MB. Stigma: a negative and a positive influence on help-seeking for adults with acquired hearing loss. Int J Audiol 2010;49:804-14.

21 Cienkowski KM, Pimentel V. The hearing aid 'effect' revisited in young adults. Br J Audiol 2001;35:289-95.

22 Southall K, Jennings MB, Gagné J-P. Factors that influence disclosure of hearing loss in the workplace. Int J Audiol 2011;50:699-707. 
23 Southall K, Gagné J-P, Leroux T. Factors that influence the use of assistance technologies by older adults who have a hearing loss. Int $J$ Audiol 2006;45:252-9.

24 Knudsen LV, Oberg M, Nielsen C, et al. Factors influencing help seeking, hearing aid uptake, hearing aid use and satisfaction with hearing AIDS: a review of the literature. Trends Amplif 2010;14:127-54.

25 Turan JM, Elafros MA, Logie $\mathrm{CH}$, et al. Challenges and opportunities in examining and addressing intersectional stigma and health. $B M C$ Med 2019;17:1-15.

26 Borkowski E. Colour and fashion: evolution of the mobility cane. Int $\mathrm{J}$ Orientat Mobil 2009;2:65-72.

27 World Federation of the Deafblind. Red and white Canes - and persons with deafblindness, 2020. Available: https://www.wfdb.eu/ deafblind-awareness-red-and-white-canes/ [Accessed 8 May 2020].

28 Baum F, MacDougall C, Smith D. Participatory action research. J Epidemiol Community Health 2006;60:854-7.

29 Dyzel V, Oosterom-Calo R, Worm M, et al. Assistive technology to promote communication and social interaction for people with Deafblindness: a systematic review. Front Educ 2020;5:578389.

30 Monti L, Delnevo G. On improving GlovePi: towards a many-to-many communication among deaf-blind users. 2018 15th IEEE Annual Consumer Communications \& Networking Conference (CCNC), Las Vegas, NV, 2018:1-5

31 Ozioko O, Navaraj W, Hersh M, et al. Tacsac: a wearable haptic device with capacitive touch-sensing capability for tactile display. Sensors 2020;20:4780-15.

32 Ozioko O, Hersh M. Development of a portable two-way communication and information device for Deafblind people. Stud Health Technol Inform 2015;217:518-25.

33 Ozioko O, Karipoth P, Hersh M, et al. Wearable assistive tactile communication interface based on integrated touch sensors and Actuators. IEEE Trans Neural Syst Rehabil Eng 2020;28:1344-52.

34 Arndt K. Conducting interviews with people who are Deafblind: issues in recording and transcription. Field methods 2011;23:204-14.

35 Jaiswal A, Aldersey H, Wittich W. Conducting qualitative research with individuals living with deafblindness. London: Sage Publications Ltd, 2020.

36 American Association of the Deaf-Blind, Helen Keller National Center. Trends and unresolved issues impacting individuals who are deaf-blind, 2010. Available: http://aadb.org/information/ncd/ncd introduction.html [Accessed 25 Mar 2020].

37 Jaiswal A, Aldersey HM, Wittich W, et al. Using the ICF to identify contextual factors that influence participation of persons with deafblindness. Arch Phys Med Rehabil 2019;100:2324-33.

38 Jaiswal A, Aldersey HM, Wittich W, et al. Meaning and experiences of participation: a phenomenological study with persons with deafblindness in India. Disabil Rehabil 2020;42:2580-92.

39 Ehn M, Anderzén-Carlsson A, Möller C, et al. Life strategies of people with deafblindness due to Usher syndrome type $2 \mathrm{a}$ - a qualitative study. Int J Qual Stud Health Well-being 2019;14:1656790.

40 Davis S. Rehabilitation: the use of theories and models in practice. Edinburgh: Elsevier Churchill Livingstone, 2006.

41 World Health Organization. International classification of functioning, disability, and health. ICF, Geneva: World Health Organization, 2001.

42 Granberg S. Functioning in adults with hearing loss. In: Manchaiah V Danermark B, eds. The experience of hearing loss. journey through aural rehabilitation. New York: Routledge, 2017: 17-28.

43 Arksey H, O'Malley L. Scoping studies: towards a methodological framework. Int J Soc Res Methodol 2005;8:19-32.

44 Tricco AC, Lillie E, Zarin W, et al. PRISMA extension for scoping reviews (PRISMA-ScR): checklist and explanation. Ann Intern Med 2018;169:467-73.

45 Peters MDJ, Godfrey CM, Khalil H, et al. Guidance for conducting systematic scoping reviews. Int J Evid Based Healthc 2015;13:141-6.

46 Dammeyer J. Deafblindness and dual sensory loss research: current status and future directions. World J Otorhinolaryngol 2015;5:37-40.

47 Dammeyer J. Prevalence and aetiology of congenitally deafblind people in Denmark. Int J Audiol 2010;49:76-82.

48 Wittich W, Southall K, Sikora L, et al. What's in a name: Dual sensory impairment or deafblindness? Br J Vis Impair 2013;31:198-207.

49 World Health Organization. Disability: assistive devices and technologies, 2020. Available: https://www.who.int/disabilities/ technology/en/ [Accessed 22 Apr 2020].
50 Simcock P, Wittich W. Are older deafblind people being left behind? A narrative review of literature on deafblindness through the lens of the United Nations Principles for Older People. J Soc Welfare Fam Law 2019;41:339-57.

51 Jaiswal A, Aldersey H, Wittich W, et al. Participation experiences of people with deafblindness or dual sensory loss: a scoping review of global deafblind literature. PLoS One 2018;13:e0203772.

52 McGilton KS, Höbler F, Campos J, et al. Hearing and vision screening tools for long-term care residents with dementia: protocol for a scoping review. BMJ Open 2016;6:e011945.

53 Cieza A, Geyh S, Chatterji S, et al. ICF linking rules: an update based on lessons learned. J Rehabil Med 2005;37:212-8.

54 Cieza A, Fayed N, Bickenbach J, et al. Refinements of the ICF linking rules to strengthen their potential for establishing comparability of health information. Disabil Rehabil 2019;41:574-83.

55 Granberg S, Möller K, Skagerstrand A, et al. The ICF core sets for hearing loss: researcher perspective, part II: linking outcome measures to the International classification of functioning, disability and health (ICF). Int $J$ Audiol 2014:53:77-87.

56 Levac D, Colquhoun H, O'Brien KK. Scoping studies: advancing the methodology. Implement Sci 2010;5:69.

57 Sandelowski M. Focus on research methods: whatever happened to qualitative description? Res Nurs Heal 2000;23:334-40.

58 Emerson J, Bishop J. Videophone technology and students with deaf-blindness: a method for increasing access and communication. $J$ Vis Impair Blind 2012;106:622-33.

59 Meyer C, Hickson L, Fletcher A. Identifying the barriers and facilitators to optimal hearing aid self-efficacy. Int $J$ Audiol 2014:53:S28-37.

60 Wittich W, Southall K, Johnson A. Usability of assistive listening devices by older adults with low vision. Disabil Rehabil Assist Technol 2016:11:564-71.

61 Cantin S, De Abreu Cybis W, Trudeau S, et al. Assessment of a communication assistive technology for individuals with Deafblindness: a case study. JDBSC 2019;5:73-95.

62 St-Amour L, Jarry J, Wittich W. The Audibility of low vision devices with speech output used by older adults with dual sensory impairment. Optom Vis Sci 2019;96:345-53.

63 Cantin S, de Abreu Cybis W, Durocher N. Setup by a person with deafblindness of a face-to-face communication assistive technology based on generally available applications. Disabil Rehabil Assist Technol 2020:1-7.

64 Jaiswal A, Fraser S, Wittich W. Barriers and facilitators that influence social participation in older adults with dual sensory impairment. Front Educ 2020;5:127.

65 Parker AT, Swobodzinski M, Brown-Ogilvie T, et al. The use of Wayfinding Apps by Deafblind travelers in an urban environment: insights from focus groups. Front Educ 2020;5:572641.

66 Centre for Welfare and Social Issues. The Nordic definition of deafblindness., 2016. Available: http://www.kuurosokeat.fi/tiedosto/ nordic_definition.pdf [Accessed 18 Jul 2018].

67 European Parliament. Rights of deafblind people, 2004. Available: https://www.europarl.europa.eu/sides/getDoc.do?pubRef=-//EP// TEXT+TA+P5-TA-2004-0277+0+DOC+XML+V0//EN [Accessed 28 Apr 2020].

68 Fraser S, Beeman I, Southall K, et al. Stereotyping as a barrier to the social participation of older adults with low vision: a qualitative focus group study. BMJ Open 2019;9:e029940-8.

69 Wittich W, Lorenzini M-C. Exploring the lived experience of older adults with dual sensory impairment. PsyArXiv 2019.

70 lezzoni LI, Kurtz SG, Rao SR. Trends in U.S. adult chronic disability rates over time. Disabil Health J 2014;7:402-12.

71 Story MF. Maximizing usability: the principles of universal design. Assist Technol 1998;10:4-12.

72 Nguyen T, Graham ID, Mrklas KJ, et al. How does integrated knowledge translation (IKT) compare to other collaborative research approaches to generating and translating knowledge? learning from experts in the field. Health Res Policy Syst 2020;18:1-20.

73 Theil A, Buchweitz L, Fuentes M. Co-designing assistive tools to support social interactions by individuals living with Deafblindness 2020:79-83. 